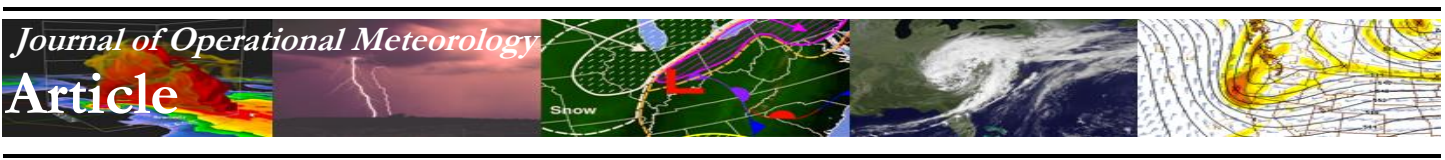

\title{
A Community Frost/Freeze Susceptibility Operational Guidance Tool
}

\author{
BETH L. HALL, MICHAEL S. TIMLIN, MARY E. WOLOSZYN, ZOE A. ZALOUDEK, and STEVEN D. HILBERG \\ Midwestern Regional Climate Center, Illinois State Water Survey, Prairie Research Institute, \\ University of Illinois, Champaign, Illinois \\ PATRICK E. GUINAN \\ University of Missouri, Columbia, Missouri \\ JEFFREY ANDRESEN \\ Michigan State University, East Lansing, Michigan \\ ALLAN C. CURTIS \\ NOAA/National Weather Service, Des Moines, Iowa \\ RAY WOLF \\ NOAA/National Weather Service, Davenport/Quad Cities, Iowa \\ PATRICK J. SPODEN \\ NOAA/National Weather Service, Paducah, Kentucky
}

(Manuscript received 27 May 2014; review completed 22 December 2014)

\begin{abstract}
Widespread frost or freeze events can cause extreme economic losses to the agriculture, horticulture, and nursery industries. Coordinated advance notice of an imminent freeze event can help minimize these losses. Forecasters can issue headlines ahead of these events if damage to susceptible vegetation is possible. Combining expertise among the forecasters and the vegetation specialists can provide a community collaborative opportunity that will inform the risks, susceptibility, and environmental conditions associated with frost and freeze impacts. The Midwestern Regional Climate Center has become the facilitator of this community collaboration effort through the development of the online Vegetation Impact Program and Frost/Freeze Guidance Project. This paper presents the development of these initiatives along with early results and findings.
\end{abstract}

\section{Introduction}

Every fall, winter, and spring, many agronomic crops, home landscapes, and nurseries run the risk of cold injury caused by freezing temperatures. Depending upon the plant species, damage can be caused by anything from a light frost to a prolonged period of sub-freezing temperatures. Major row crops may be susceptible to damage in the spring if a freeze occurs after planting, and yields and crop quality may be reduced if an early freeze occurs in the fall.

Damaging freeze events can have a significant economic impact on agricultural, horticultural, and nursery industries. The impacts include not only the direct damages of crop loss, but also indirect impacts such as loss of income for producers, higher prices for consumers, and loss of industry-related jobs. These events can be especially damaging to growers of specialty crops, such as fruits. Examples of such losses are numerous:

- In December 1983, a Christmas cold wave caused citrus losses of $\$ 1$ billion in Florida, hundreds of millions in Texas, $\$ 15$ million in Tennessee, and $80 \%$ of the crop in Louisiana-according to insurance report estimates [(National Climatic Data Center (NCDC) 1983]. 
- A freeze event in April 2012 destroyed much of Michigan's fruit crops, with only 5-10\% production (McMillin 2013). In the Lake Erie and Niagara Concord grape-growing region, 29000 acres were impacted with an estimated farm loss due to the freeze of nearly \$14 million (Martin and Weigle 2013). Direct losses overall varied depending upon the area and resource impacted (Wood 2014).

- The Easter Freeze of April 2007 was estimated to have resulted in $\$ 146$ million in losses, including $\$ 106$ million to winter wheat, $\$ 12.4$ million to peaches, $\$ 10$ million to apples, and $\$ 18$ million to alfalfa (Wolf et al. 2008). Impacts from this event were widespread across the Midwest and Southeast regions, affecting at least 12 states (Angel 2007). The overall estimated cost to the fruit crop, row crop, and ornamental tree industry in 14 states was $\$ 2.2$ billion (NCDC 2012).

- In May 2010, snow and cold weather devastated the ginseng crop in northern Wisconsin. Wisconsin produces $95 \%$ of the United States crop of ginseng and is a major exporter to China. The winter-like weather hit before growers could take steps to protect their crops. Mature plants that froze went dormant and lost a year of growth, while seedlings were killed or severely weakened. The majority of ginseng, about 1400 acres, is grown in Marathon County, Wisconsin, and is worth $\$ 60$ 000-80 000 per acre. Initial estimates are that $80-90 \%$ of the crop in Marathon County was damaged by the snow and cold (Herzog 2010).

Whereas not all losses from damaging freeze events can be avoided, there are several preventative measures that could be employed to prevent cold injury if enough lead time is provided. Several examples include irrigating or spraying the vegetation, using wind machines to promote mixing of nearsurface air to inhibit frost formation, covering plants, relocating plants to a warmer environment, or utilizing well-placed heaters (Perry 2013).

Forecasters might use the median climatological date of the first/last freeze or a set calendar date to determine whether advisories or warnings should be issued. In their area of responsibility, they may lack the specific knowledge of the variety and types of crops (including horticulture), crop-specific damage thresholds, and if crops have reached the point in their growing cycle when they are susceptible to frost damage. It is a challenge for forecasters to have this information available and synthesized in order to provide useful advisories and warnings. Farmers, horticulturalists, and nursery operators need to know the climatological risks of a potentially damaging freeze event, and within that context, the risk of critically low air temperatures occurring during the upcoming 24-72 h. Whereas there are insurance options that can help protect against the loss from a freeze event, these payouts are not available for all crops and often are dependent upon climatological normal dates that may or may not be relevant in a given year if planting is early or if phenological development (for overwintering crops) is advanced (Angel 2007; Wolf et al. 2008).

Accordingly, an operational, real-time exchange of information between forecasters and agricultural experts where both groups could share their knowledge, information, and resources would be mutually beneficial and help to minimize these potentially significant losses. To date there is no known, widespread, consistent system in place to promote the exchange of timely information or to help monitor the impacts of freeze events. In some cases there may not be a sufficient and quantifiable method of reporting these losses.

The implementation of an information exchange and impact tracking system would be a significant step in aiding weather forecasters in the issuance of timely, useful advisories and warnings for potential cold damage. In addition, risk management tools associated with the system could be developed to aid growers in making decisions about planting dates, crop protection, or crop management.

\section{Background}

a. Precedent for community involvement for impact awareness and prevention

Partnerships between weather forecasters, climatologists, and local communities are not unprecedented. A deadly flash flood hit Fort Collins, Colorado, in July 1997. Rainfall varied from 368.3 $\mathrm{mm}$ (14.50 in) west of Fort Collins to a little over 76.2 $\mathrm{mm}$ (3 in) at the National Weather Service (NWS) cooperative network weather station (Fort Collins $4 \mathrm{E}$; Doesken and McKee 1998) on the Colorado State University campus. The flash flooding resulted in several fatalities and $>\$ 200$ million in property damage (Cifelli et al. 2005). In addition, citizen reports of rainfall, rain rate, and flooding helped with the event analysis. Encouraged by the public response, the Colorado Climate Center began to organize a network 
of observers, and by 1998 the Community Collaborative Rain, Hail, and Snow Network (CoCoRaHS; www.cocorahs.org, Cifelli et al. 2005) was established. The network offered a simple, Internet-based system where volunteer users could submit their daily precipitation readings online and the data would be archived and presented in value-added products across the region. Within days, $>150$ people volunteered (Cifelli et al. 2005). By the end of 2009, all 50 states had joined CoCoRaHS, and by March 2013, >40 000 people had signed up as CoCoRaHS volunteers. Not only have all of these data reports contributed to a variety of research projects regarding the variable nature of precipitation, but also weather forecasters, climatologists, and hydrologists are regularly watching the daily reports to CoCoRaHS to learn more about the hydrologic environment.

Over the past $100 \mathrm{yr}$, whether it was the Dust Bowl of the 1930s, the extensive drought of the 1950s, or even the relatively short but crippling droughts of 1988 and 2008-present (e.g., the Texas/Oklahoma region), drought has had an impact on many weatherdependent sectors-ranging from agriculture to transportation and tourism. In 1995, the National Drought Mitigation Center (NDMC) was established to better understand and monitor drought. The United States Drought Monitor (USDM, droughtmonitor.unl.edu/) is an online system that was created to help not only track varying types of drought across the United States, but to better understand the spatial extent and intensity of drought (Svoboda et al. 2002). Contributors from the NDMC, United States Department of Agriculture (USDA), Climate Prediction Center, and NCDC collect input from experts and data observation networks across the country to derive maps to track the intensity, type, and trends in drought. Since 2005, the Drought Impact Reporter (droughtreporter.unl.edu/) that monitors the impacts of drought has augmented these data. This is an interactive tool that collects, quantifies, and synthesizes drought impact reports. The tool is a combination of individual submissions, online drought-related news reports, and contributions from the media and others sources. This tool not only collects the information, but also provides researchers and decision-makers access to quantifiable data to assess the extent, intensity, and impacts of different types of drought. Without this input from the drought community, the USDM maps would be much less effective in tracking the state of drought across the country.

\section{b. Motivation for community frost/freeze collaboration}

A devastating freeze event in April 2007 caused $>\$ 2$ billion of loss impacting >12 states (Angel 2007; Wolf et al. 2008). An unseasonably warm March set the stage for the event, resulting in unusually early growth and phenological development of perennial vegetation. This left the vegetation much more vulnerable than normal to cold injury. An Arctic air mass entered the region in early April with a sustained period of unseasonably low temperatures that resulted in widespread, costly damage to an extensive range of crops and natural vegetation. Review of forecast guidance for this event indicated that there was 6-10 days lead time of a cold wave, and with very good 3day forecasts. There were even efforts made to disseminate the potential severity of the upcoming event to the public via the Internet and media contacts (Wolf et al. 2008). Even though the event was devastating and the forecast efforts were determined to be good, a technical report (Wolf et al. 2008) released following the event concluded:

Findings from a survey of Central Region weather forecast offices (WFOs) indicate services could be improved by establishing and utilizing closer ties with University Extension Service specialists and USDA field offices. Specifically, input from University Extension Service specialists should be used to determine the need for Freeze/Frost products each season, not solely calendar dates or climatology. Second, USDA field offices, in particular the Farm Services Agency, can be an excellent source of impact information for regional reports and Storm Data.

The establishment of communication between 122 NWS WFOs across the United States [23 WFOs in the Midwestern Regional Climate Center (MRCC) region; 38 in the NWS Central Region] and the University Extension Services or any other partner with expertise on vegetation vulnerabilities and current conditions constituted a huge task. This initially began with each individual WFO attempting to coordinate with agricultural experts in their state. This effort to coordinate state experts, climatologists, land-grant extension personnel, and NWS forecasters did not always result in agreement on pre-planning standards and criteria for frost/freeze-related messages to the users. Often, the resulting map of freeze-related headlines appeared like a mosaic of conflicting informa- 
tion. Further, the resulting state, regional, and national warning maps, combined from individual WFO county warning areas (CWA) of responsibility, resulted in conflicting information regarding freeze potentials.

There are several local factors that play a role in the risk for low air temperatures to cause damage to vegetation. First, while widespread freeze events can occur, episodic freeze events also occur that vary spatially and temporally in impact owing to diverse vegetation types and topographic conditions that affect local temperatures. While forecasters might be able to observe the state of vegetative development in and around their immediate location, CWAs encompass a much larger area (e.g., diameter $\geq 300 \mathrm{~km}$ ). Forecasters might be aware of localized concerns about a potential freeze event that may not pertain to the full CWA. Further, without input from the industry experts about specific crops, they often are left to make a decision that is more general. In addition, the frequency and magnitude of freeze events typically are dependent on microclimatic factors such as local topography and soil type, so their severity may vary greatly over relatively small areas (Andresen and Winkler 2009). For example, cool air tends to pool into low-level locations, whether in valleys between mountain ranges or simply shallow areas across relatively flat land. However, this leaves the vegetation more susceptible to lower temperatures than at nearby higher locations. To complicate matters further, each type of vegetation is susceptible to not only a unique temperature threshold where damage can occur, but the level of susceptibility also can be highly dependent upon the stage of growth of the vegetation. Vegetation in its dormant or rest stage (e.g., fruit trees during winter) is typically most resistant to cold damage. However, as vegetative growth and development proceed during the spring season, the damage threshold typically increases significantly. For example, the cold damage threshold for tart cherries at full dormancy can be as low as $-31.7^{\circ} \mathrm{C}\left(-25^{\circ} \mathrm{F}\right)$ but increases to $-2.2^{\circ} \mathrm{C}\left(+28^{\circ} \mathrm{F}\right)$ at the full bloom stage (Dennis and Howell 1974). Note that because of the operational nature of this online project for the contiguous United States, all temperature units for the maps are presented in ${ }^{\circ} \mathrm{F}$, and run times of updated maps are noted in central time.

Given these factors, Wolf et al. (2008) offered several recommendations to attempt to minimize such devastating losses from future freeze events. Two key recommendations are repeated here:
1) Issuance of freeze warnings should be based on potential impacts to agriculture, horticulture, nurseries, and home gardens rather than calendar dates. Variable climatic conditions from year to year result in the freeze threat not necessarily occurring at the same time every fall and spring.

2) Ties with university extension service specialists, state climatologists, USDA farm service agencies, and other partners should be developed and utilized to:

a) determine when freezing temperatures are a threat and

b) gather quality, detailed post-event impact information for regional reports and event documentation (e.g., NCDC's Storm Data).

\section{The Vegetation Impact Program (VIP)}

In the fall of 2012, NWS offices in Milwaukee/ Sullivan, Wisconsin, and Paducah, Kentucky, contacted the MRCC, located in the Illinois State Water Survey of the Prairie Research Institute at the University of Illinois at Urbana-Champaign. Each office separately asked if the MRCC could help facilitate a means of communication not only between the NWS and the vegetation community of experts, but also among various NWS offices. The MRCC is one of six Regional Climate Centers (RCCs) in the United States contracted through the National Oceanic and Atmospheric Administration (NOAA) to provide regional climate service support. Over their $30 \mathrm{yr}$ of existence, the RCCs have developed the ability to provide tailored climate services to users with a variety of concerns (e.g., health, energy, agriculture, and insurance) over large regions - nine states in the case of the MRCC. Important aspects of climate services include the networking of climate stakeholders across sectors, development of online climate monitoring tools, and region-related applied climate research.

After working with the NWS, state climatologists, and people in the field of vegetation expertise, the MRCC realized the need to develop the Vegetation Impact Program (VIP; mrcc.isws.illinois.edu/VIP/) in the summer of 2013 to offer vegetation-related climate monitoring tools beyond those related specifically for frost/freeze concerns. The VIP is a partnership among the MRCC, weather forecasters, climatologists, members of vegetation-related industries, and other experts in order to provide the best possible climatological resources to continually monitor and understand the current state of the vegetation-climate 
environment. Serving as the host institution for the VIP and facilitating communication between participants, the MRCC has the opportunity to help minimize the devastating impacts of climate and weather on vegetation through stakeholder networking and operational product tool development. Potential impacts on vegetation, whether it is associated with agriculture, horticulture, nurseries, or home gardeners, can expand beyond frost/freeze events to include things like heat stress, accumulated chilling hours for fruit, and drought.

\section{a. Frost/Freeze Project (FFP)}

The inaugural project that formed under VIP is the Frost/Freeze Project (FFP). Inspired by both recent damaging freeze events and the needs of NWS offices, the main missions of the FFP were to (1) provide a suite of operational monitoring and climatological tools to help users track the state of the vegetationclimate environment and (2) establish a means of communication among forecasters, climatologists, and vegetation experts that provide input guidance on the state of the vegetation-climate environment and quantitative impacts from damaging freeze events. Such a project should help minimize future vegetation impacts and help advance the understanding of the relationships between a variety of vegetation and atmospheric conditions through applied research.

\section{b. Early accomplishments of the VIP/FFP}

By late fall 2012, during the infancy of the FFP, an email list server was established that allows forecasters, climatologists, and expert observers to subscribe and communicate with each other on the status of their local vegetation-climate environment. As of late spring 2013, >180 subscribers had enrolled across 16 states. Users can subscribe online and once subscribed, communicate online or offline with fellow participants on issues such as guidance, vegetative- or climaterelated questions, and research.

The FFP has developed a number of operational products that either did not exist previously, or existed only at local institutions. Currently developed products include graphs, static maps, and geographic information system (GIS)-based web applications. All products for the FFP are developed based on input from both staff at the MRCC and subscribers to ensure that as many options and approaches are considered as possible.
A group of static maps are developed each day from in situ observational data from the RCC's database-Applied Climate Information System (ACIS). The first map sets using both a $-2.2^{\circ} \mathrm{C}\left(28^{\circ} \mathrm{F}\right)$ and a $0.0^{\circ} \mathrm{C}\left(32^{\circ} \mathrm{F}\right)$ freezing threshold include the date of the first freeze, date of most recent freeze, the number of days since most recent $-2.2^{\circ} \mathrm{C}\left(28^{\circ} \mathrm{F}\right)$ freeze to consider possible growth initiation (Fig. 1), and the number of days with minimum temperature $<-2.2^{\circ} \mathrm{C}$ $\left(28^{\circ} \mathrm{F}\right)$ within the past 14 days. There are maps showing the lowest minimum temperature so far for that season. Finally, growing degree-day (GDD) and modified GDD maps are made with accumulations since the date of last $-2.2^{\circ} \mathrm{C}\left(28^{\circ} \mathrm{F}\right)$ and $0.0^{\circ} \mathrm{C}\left(32^{\circ} \mathrm{F}\right)$ freezes. To make the tools applicable to many different plants, current base temperatures for the GDD maps are $5.6,7.2,10.0$, and $12.2^{\circ} \mathrm{C}\left(42,45,50\right.$, and $\left.54^{\circ} \mathrm{F}\right)$.

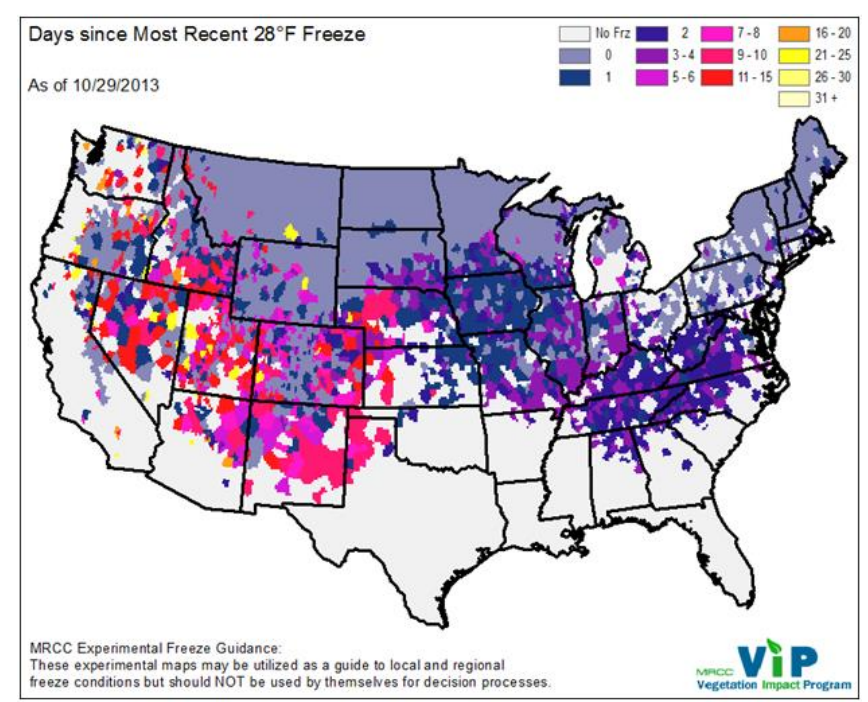

Figure 1. Example of one of the static online maps, showing the days since the most recent $-2.2^{\circ} \mathrm{C}\left(28^{\circ} \mathrm{F}\right)$ temperature-useful for assessing the vulnerability of vegetation to the next freeze in the fall. Click image for an external version; this applies to all figures hereafter.

In addition to the static maps, an interactive GISbased web map application was created to showcase these data in a more interactive format (Fig. 2). The station points and interpolated raster datasets shown in the above-mentioned maps are made available through this application. The web map application also allows users to focus on specific locations and view detailed data for each station.

In addition to map and GIS-based products, the MRCC also produces and develops graphical products, including frost-freeze probabilities (Fig. 3) based on in 


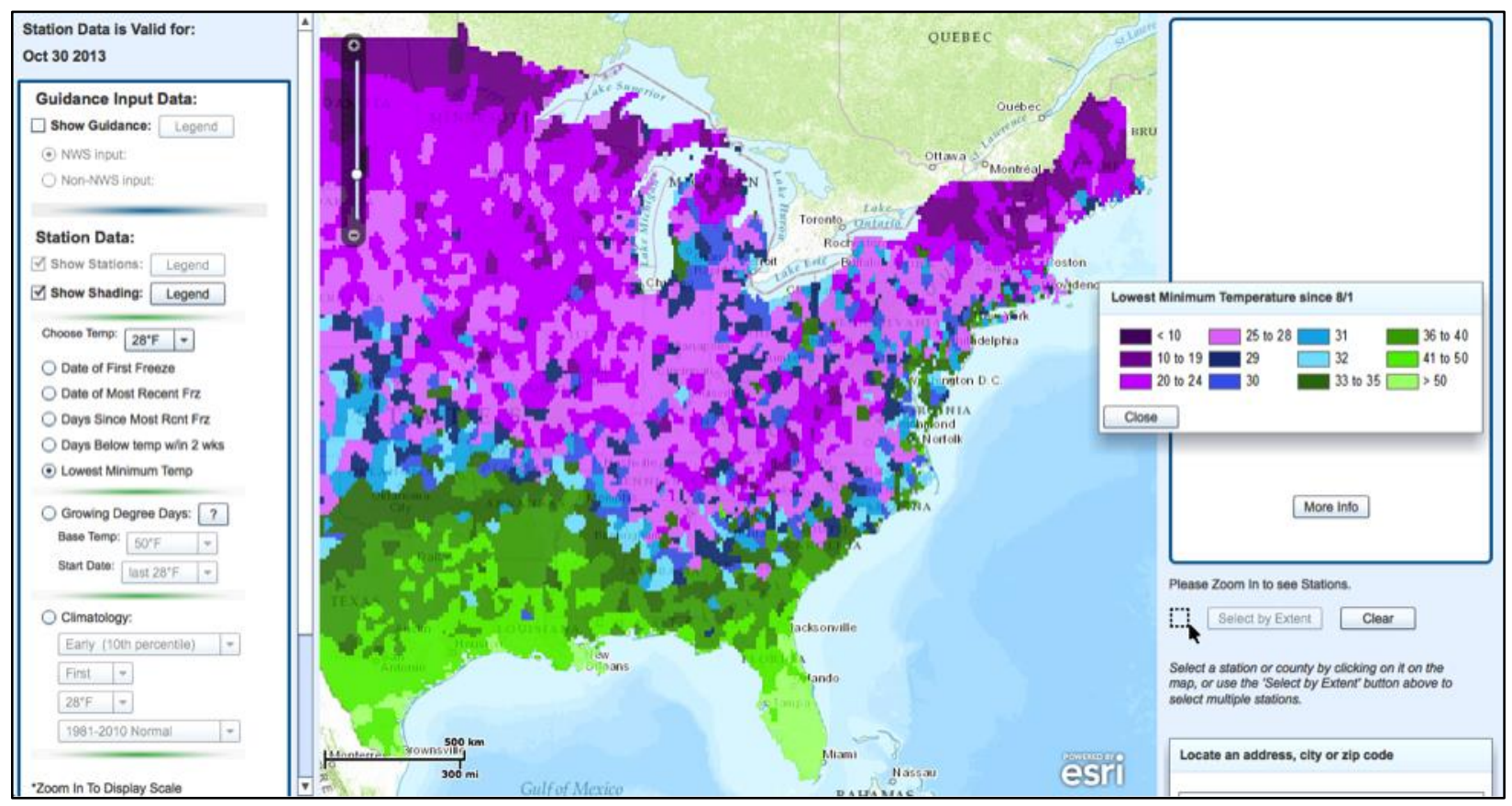

Figure 2. Example of the online GIS interactive tool showing the interpolation of lowest minimum temperature $\left({ }^{\circ} \mathrm{F}\right)$.

\section{Freeze Probabilities \\ URBANA (IL) \\ USC00118740 \\ 1981 - 2010}

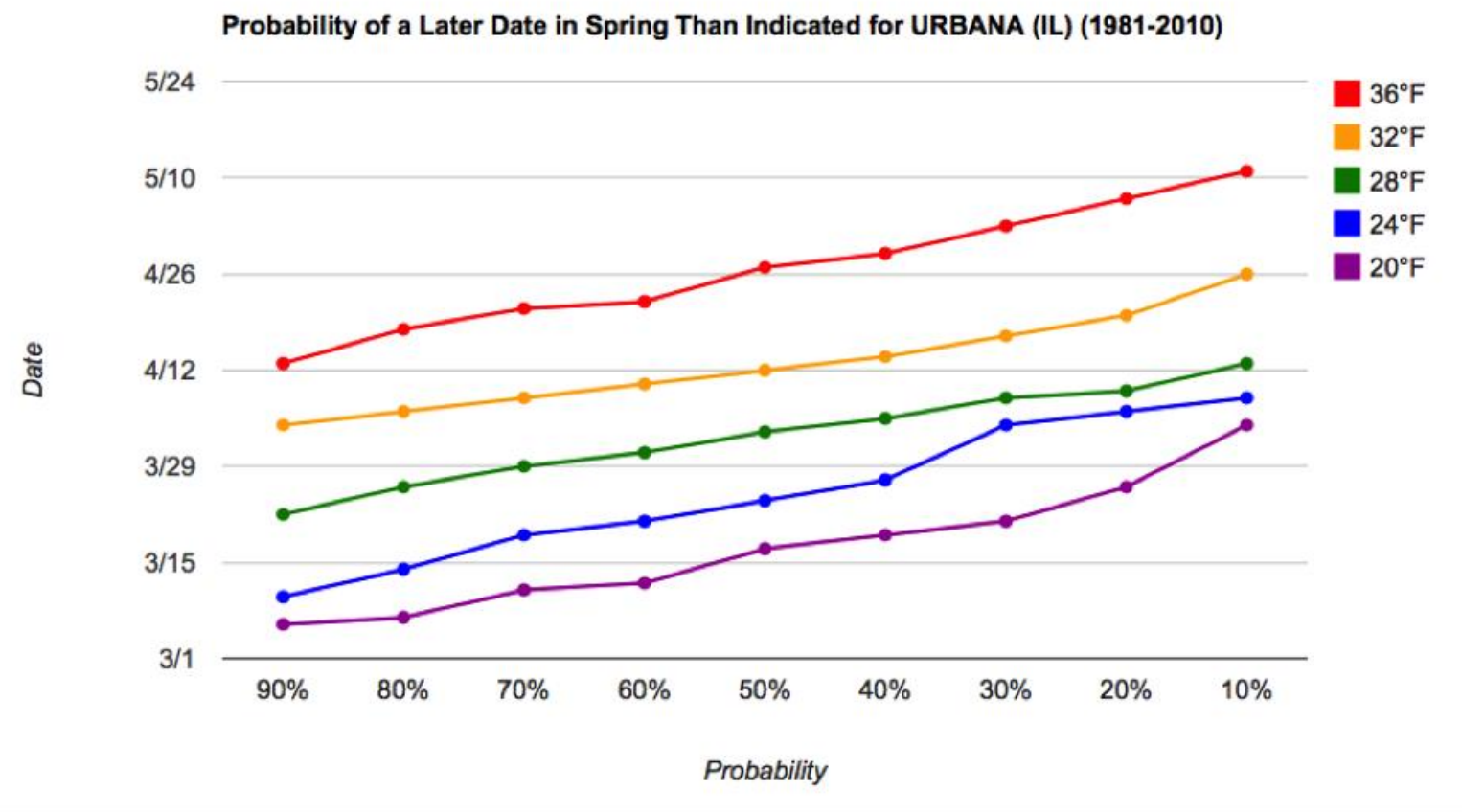

Figure 3. Example of the frost/freeze probability product for Urbana, IL, showing the probability of a late spring freeze at selected temperature thresholds $\left({ }^{\circ} \mathrm{F}\right)$. 
situ observational data for a user-defined historical period.

One of the major goals of the FFP is to help NWS WFOs communicate with each other and with collaborators outside of the NWS. Thus, a frost/freeze warning guidance input webpage was created (Fig. 4). On this webpage, users log in, select their counties of interest - sorted by county warning area, crop reporting district, or state-and report whether those counties are in a situation where freeze advisories may need to be issued. In addition to selecting the counties for guidance, the user also has the ability to add comments to help others view the reasoning behind their decision. This information is saved to a database so that it can be mapped and examined for later analyses, such as the evaluation of guidance and severe event case studies.

Every $30 \mathrm{~min}$, two sets of advisory maps are created from these data showing the most recent status of the counties. One map set is based only on NWS input (Fig. 5), and the other set is based on input from other experts (not shown)-such as agriculture extension offices, state climatologists, and the agriculture/horticulture community at large. These data also are available for viewing in the GIS interactive map application, which includes additional symbology showing how recently the guidance report was submitted. Users of the GIS map also can access all guidance input reports for a county.

Similar to the frost/freeze warning guidance input webpage, a freeze-impact input webpage also was created for users to report observed effects of a frost or freeze (Fig. 6). Here, users are able to select affected counties and enter information such as date of freeze, date impact was noticed, estimated value of loss, and general comments including what vegetation was affected. These data also are stored in a database and used to create maps twice daily for the number of impact reports by county. Moreover, these data are available for viewing in the GIS-based map, where users can access all impact reports for a county and view the details of each report.

When dealing with impacts of this nature, it is important to note that the goal is not to catch every single impact, but rather to make users aware of the geographical scope, type, and severity of impacts that are occurring. It also is important to understand that the information is not intended for aid-funding decisions, such as insurance claims.

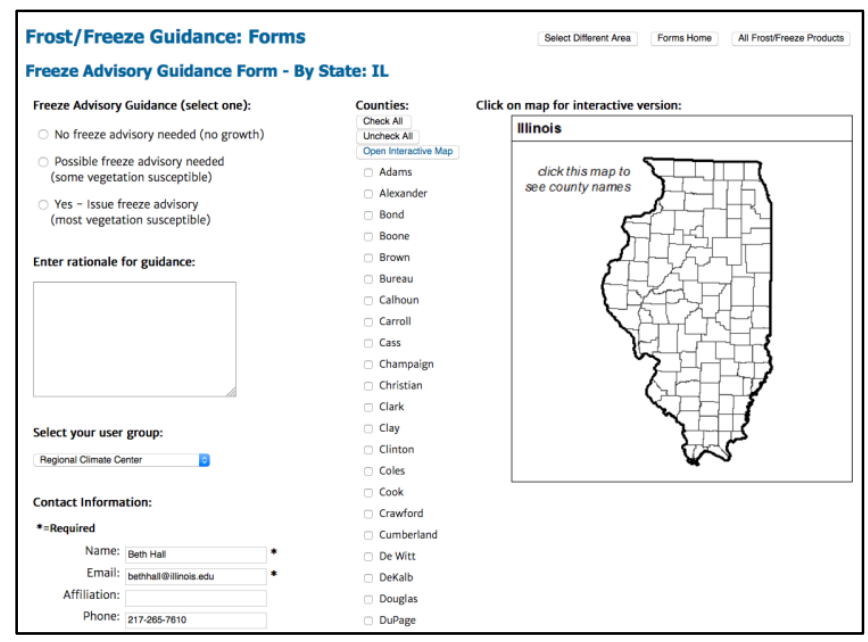

Figure 4. Example of the online frost/freeze guidance webpage. Users provide input on whether frost/freeze headlines should be issued in their area given existing vegetation conditions on the ground.

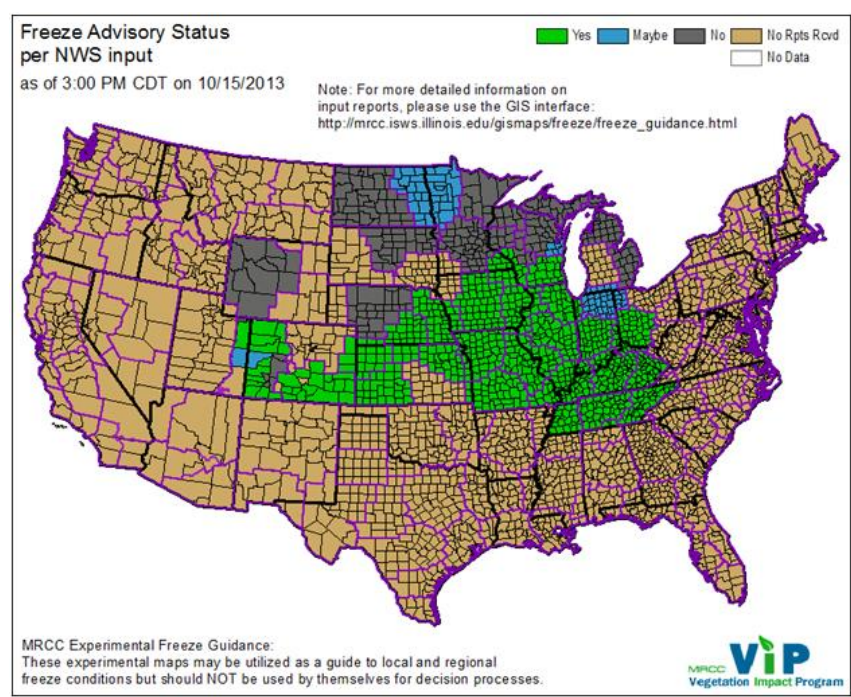

Figure 5. Example map based on guidance input reports across the domain.

\section{c. Positive early impacts on NWS product delivery}

The availability of the suite of FFP graphics has proven beneficial for the coordination of and subsequent generation of frost/freeze headlines. The ability of NWS forecasters to visualize the geographical placement and progression of various vegetationclimate impacts is paramount in delivering the best possible customer-focused frost/freeze guidance. While the FFP can be improved with increased vegetation-expert participation via the guidance input webpage, the already modest and growing input by WFO forecasters and vegetative experts has provided 


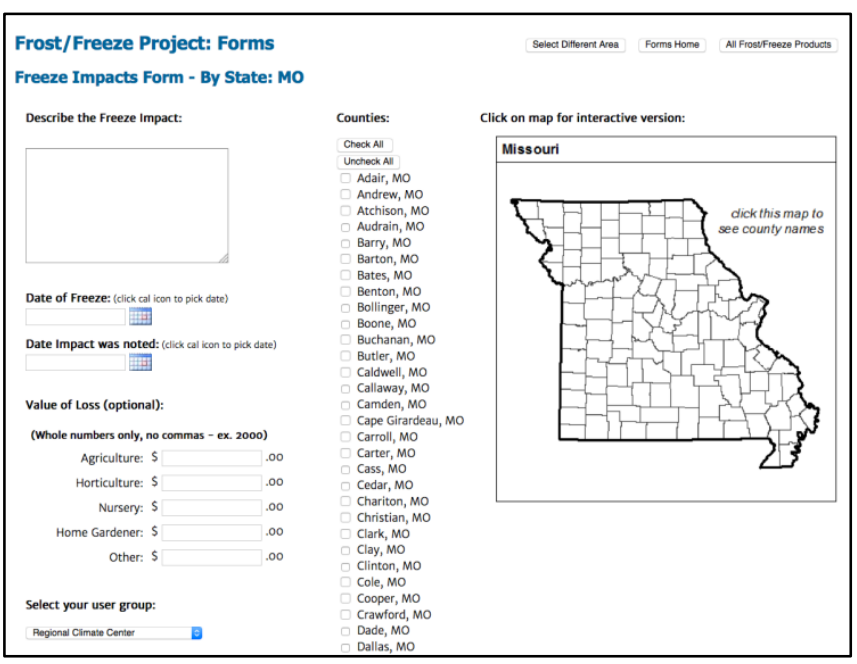

Figure 6. Example of the online form for reporting impacts from actual frost/freeze events.

invaluable visual tools for the coordination and subsequent issuance of frost/freeze headlines. The efficiency of NWS coordination in issuing accurate and timely headlines has markedly improved based upon forecaster feedback.

Increased FFP participation and input from plant experts is a key to realizing even greater benefit from the FFP. In addition, further training of NWS forecast staff-including more robust advertisement of the FFP graphical guidance products - is important to the optimal provision of frost/freeze headlines.

\section{d. Challenges thus far}

After one year of development and implementation, there have been many successes to celebrate, but also several challenges that were encountered. The first challenge was recruiting participants to subscribe to the list server and submit guidance input. Because the NWS was the group of stakeholders requesting such an interdisciplinary operational communication tool, recruiting participants from almost every office in the region was relatively straightforward. Identifying, inviting, and encouraging vegetation expert observers to get involved, however, was more challenging. At the beginning of the project, there was a limited list of individuals to invite (e.g., state climatologists who often could recommend university extension personnel). Unfortunately, there were many areas across the project's spatial domain where industry experts were left unidentified; this challenge is ongoing. Ways to respond to this challenge will be sought through the distribution of marketing materials, presentations at stakeholder meetings, and publications in key journals.
Another challenge was the need to train the subscribers on how to submit input and what the various input categories indicate. Feedback from several subscribers indicated an interest in participating, but also showed a lack of clarity about the input process and resulting products. Therefore, both live and recorded webinars were provided in September 2013 describing how the system works and what is needed from participants. These webinars were tailored to the separate groups of participants (e.g., forecasters versus vegetation experts) as their input contributions differ. An online question and answer page also is being developed where new and current subscribers may find additional information.

There has been much positive feedback at the national scale since this project's inception. Even though initially developed for the northern agricultural states from Colorado to Ohio and from Tennessee to the northern United States border, forecasters and vegetation experts from beyond this region expressed an interest in these online operational tools expanding nationally. Whereas it may seem relatively simple at first to expand the spatial domain, there are both regionally specific climatological and vegetation factors that are not so straightforward to handle. For example, in the north-central United States there are distinct periods throughout the year when the threat of a damaging freeze is greatest (i.e., bookending the winter/dormant season). However, for locations in the United States where winters may not induce a dormant season, the timing of damaging freeze events may not coincide with the same months as elsewhere. Therefore, further testing continues with these operational guidance tools in order to better address the scientific and operational implications of a nationwide service (i.e., in the contiguous 48 states).

As mentioned previously, most damage to vegetation came not only from daily low temperatures falling below a particular threshold, but having those low temperatures sustained for an extended period of time. To monitor this more effectively, hourly atmospheric data need to be integrated with future online tools. Although hourly data are available at the MRCC - and many states throughout the project domain have hourly mesoscale-network data-the real-time ingestion and integration with the other operational datasets is challenging. The ACIS data tool that houses daily temperature and precipitation data for the United States is organized in such a way for easy data access and manipulation. Once hourly data 
become more accessible within ACIS, then hourly operational products for the FFP can be developed.

\section{Summary}

The FFP and VIP offer unique platforms for forecasters, climatologists, and vegetation experts to collaborate on the monitoring, assessment, and research of both risk and susceptibility of vegetation to damaging frost/freeze events. Inter-community collaborations that combine atmospheric and environmental expertise are not unprecedented, with past examples including the CoCoRaHS and USDM efforts. Within a short period, members of the MRCC, NWS, universities, and vegetation expert communities have demonstrated the potential of such a collaborative effort and the desire to keep expanding the project both spatially and with the number of supporters.

Acknowledgments. The authors acknowledge Jim Keeney and John Eise of the NWS Central Region Headquarters for supporting this project and encouraging forecasters throughout their region to participate in both guidance reporting and monitoring. The MRCC would like to acknowledge the support of NOAA to provide climate services to the stakeholders of the region. This project was partially funded by NOAA contract EA133E-10-CN-0168 with additional support from the Illinois State Water Survey. Any opinions, findings, and conclusions or recommendations expressed are those of the authors and do not necessarily reflect the views of the Illinois State Water Survey.

\section{REFERENCES}

Andresen, J. A., and J. A. Winkler, 2009: Weather and climate. Michigan Geography and Geology, R. G. Schaetzl, D. Brandt, and J. T. Darden, Eds., Pearson Custom Publishing, 288-314.

Angel, J. R., 2007: The April 2007 hard freeze in Illinois: Features and impacts. Illinois State Water Survey Data/Case Study 2007-04, 32 pp. [Available online at www.sws.uiuc.edu/pubdoc/DCS/ISWSDCS2007-05.pdf.]

Cifelli, R., N. Doesken, P. Kennedy, L. D. Carey, S. A. Rutledge, C. Gimmestad, and T. Depue, 2005: The Community Collaborative Rain, Hail, and Snow Network: Informal education for scientists and citizens. Bull. Amer. Meteor. Soc., 86, 1069-1077, CrossRef.

Dennis, F. G., and G. S. Howell, 1974: Cold hardiness of tart cherry bark and flower buds. Michigan State University Farm Sciences Research Report 220, Michigan Agricultural Experiment Station, East Lansing, MI, $63 \mathrm{pp}$.
Doesken, N. J., and T. B. McKee, 1998: An analysis of rainfall for the July 28, 1997 flood in Fort Collins, Colorado. Colorado Climate Center/Department of Atmospheric Sciences, Climatology Report 98-1, 59 pp. [Available online at climate.atmos.colostate.edu/pdfs/ climo_rpt_98_1.pdf.]

Herzog, K., cited 2010: State ginseng crop crippled after May snowstorm. Milwaukee Wisconsin Journal Sentinel, 14 May 2010. [Available online at www.jsonline.com/business/93742354.html.]

Martin, K., and T. Weigle, cited 2013: Economic impact of 2012 frost and freeze events in the Lake Erie region. Cornell University College of Agriculture and Life Sciences, Viticulture and Enology Program. [Available online at grapesandwine.cals.cornell.edu/newsletters/ appellation-cornell/2012-newsletters/issue-10/economicimpact-2012-frost-and-freeze.]

McMillin, Z., cited 2013: Frozen fruit crops in West Michigan mean huge bite out of state, local economies. [Available online at www.mlive.com/business/westmichigan/index.ssf/2012/04/west_michigans_killed-off_ crop.html.]

NCDC, 1983: Storm Data, 25 (12), 60 pp. [Available online at www.ncdc.noaa.gov/IPS/sd/sd.html.] , 2013: Billion-dollar U.S. weather/climate disasters 1980-2013. Asheville, NC, 7 pp. [Available online at www.ncdc.noaa.gov/billions/events.pdf.]

Perry, K. B., cited 2013: Frost/freeze protection for horticultural crops. North Carolina State University, Horticulture Information Leaflets. [Available online at www.ces.ncsu.edu/hil/hil-705.html.]

Svoboda, M., and Coauthors, 2002: The Drought Monitor. Bull. Amer. Meteor. Soc., 83, 1181-1190, CrossRef.

Wolf, R., and Coauthors, 2008: The Easter freeze of April 2007: A climatological perspective and assessment of impacts and services. NOAA/USDA Tech. Rep. 200801, $56 \mathrm{pp}$. [Available online at www1.ncdc.noaa.gov/ pub/data/techrpts/tr200801/tech-report-200801.pdf.]

Wood, D., cited 2014: Grape freeze damage extensive in Ohio, New York, Michigan. [Available online at midwestwinepress.com/2012/05/02/grape-freezedamage-extensive-in-ohio-new-york-michigan/.] 